OPEN ACCESS

Edited by:

Mohammad Farhadinia, University of Oxford, United Kingdom

Reviewed by:

Yadvendradev V. Jhala, Wildlife Institute of India, India

Katia Maria P. M. B. Ferraz,

University of São Paulo, Brazil

*Correspondence:

Alison L. Greggor

AGreggor@sdzwa.org

Specialty section:

This article was submitted to

Animal Conservation,

a section of the journal

Frontiers in Conservation Science

Received: 13 January 2021

Accepted: 15 March 2021

Published: 08 April 2021

Citation:

Greggor AL, Berger-Tal O,

Swaisgood RR, Cooke SJ,

DeVault TL, Fernández-Juricic E,

Gienapp A, Hall S, Hostetter C,

Owen MA, Rankin S, Ruppert KA, Swaddle JP and Blumstein DT (2021)

Using Change Models to Envision Better Applications of Animal Behavior

Research in Conservation

Management and Beyond.

Front. Conserv. Sci. 2:653056.

doi: 10.3389/fcosc.2021.653056

\section{Using Change Models to Envision Better Applications of Animal Behavior Research in Conservation Management and Beyond}

\author{
Alison L. Greggor ${ }^{1 *}$, Oded Berger-Tal ${ }^{2}$, Ronald R. Swaisgood ${ }^{1}$, Steven J. Cooke ${ }^{3}$, \\ Travis L. DeVault ${ }^{4}$, Esteban Fernández-Juricic ${ }^{5}$, Anne Gienapp ${ }^{6}$, Suzanne Hall ${ }^{7}$, \\ Cameron Hostetter ${ }^{6}$, Megan A. Owen ${ }^{8}$, Shannon Rankin ${ }^{9}$, Kirstie A. Ruppert ${ }^{10}$, \\ John P. Swaddle ${ }^{11}$ and Daniel T. Blumstein ${ }^{12}$
}

${ }^{1}$ Recovery Ecology, San Diego Zoo Wildlife Alliance, Escondido, CA, United States, ${ }^{2}$ Mitrani Department of Desert Ecology, Jacob Blaustein Institutes for Desert Research, Ben-Gurion University of the Negev, Beersheba, Israel, ${ }^{3}$ Canadian Centre for Evidence-Based Conservation, Institute of Environmental and Interdisciplinary Science, Carleton University, Ottawa, ON, Canada, ${ }^{4}$ Savannah River Ecology Laboratory, University of Georgia, Aiken, SC, United States, ${ }^{5}$ Department of Biological Sciences, Purdue University, West Lafayette, IN, United States, ${ }^{6}$ ORS Impact, Seattle, WA, United States, ${ }^{7}$ Conservation Policy, San Diego Zoo Wildlife Alliance, San Diego, CA, United States, ${ }^{8}$ Conservation Science and Wildlife Health, San Diego Zoo Wildlife Alliance, Escondido, CA, United States, ${ }^{9}$ Marine Mammal and Turtle Division, Southwest Fisheries Science Center, National Marine Fisheries Service, National Oceanographic and Atmospheric Administration, La Jolla, CA, United States, ${ }^{10}$ Community Engagement, San Diego Zoo Wildlife Alliance, Escondido, CA, United States, ${ }^{11}$ Institute for Integrative Conservation, William \& Mary, Williamsburg, VA, United States, ${ }^{12}$ Department of Ecology and Evolutionary Biology, University of California, Los Angeles, CA, United States

While most animal behavior researchers have mastered the process of knowledge creation, generating knowledge that can readily be applied requires a different set of skills. The process and timeframe of fundamental scientific knowledge production is often not relevant to those who might apply it, such as conservation or wildlife managers. Additionally, the complex challenges that policy makers, managers and practitioners face are often not adequately communicated to and among scientists. This mutual disconnect in discourse, relationships, common terms, and practices is especially apparent when animal behavior researchers seek to have applied impact. We argue that bridging the complex implementation gap in animal behavior requires a formalized vision for change. We turn to change model theory, a tool commonly used in other fields for identifying the links between actions and outcomes necessary for enacting large-scale change. We focus on the subfield of conservation behavior with a change model that outlines specific ways to improve collaboration and coordination between animal behavior science and conservation practice. We present this targeted change model, review each strategy the model outlines, and highlight pressing actions that people from various career stages and backgrounds can take. We encourage researchers to further the alignment of science with management needs by developing the proper communication mechanisms for improved cultural exchange and plan future change model efforts directly targeting managers. Beyond the conservation behavior change model we present, we also discuss 
the broad applicability of change models to enhance the application of academic research to other fields. Fundamental science researchers are increasingly required to show impact of their work on society; the change model process we describe here can enable further impact.

Keywords: change model theory, conservation practice, evidence-based conservation, knowledge-application gap, relationship-building, research-implementation gap

\section{INTRODUCTION}

Many areas of animal behavior research can be used to solve reallife problems, including welfare indicators for zoo, laboratory, and farmed animals (Broom and Fraser, 2015); behavioral problems of companion animals (Marchant-Forde, 2015); and applications of behavior to conservation management (BergerTal and Saltz, 2016). Empirical animal behavior publications increasingly contain suggestions and recommendations for management and policy, and researchers are increasingly expected to have applied or broader impacts in their research outcomes, as specified by grantors (e.g., the US's National Science Foundation or Canada's Natural Sciences and Engineering Research Council) or as part of institutional assessments (e.g., the UK's Research Excellence Framework). However, simply publishing papers with implications for animal welfare or conservation is unlikely to influence policy or management decisions. We must do more as researchers if we want our animal behavior translational research to have meaningful and relevant applied impact.

Animal behavior researchers and behavioral ecologists are not alone in facing such issues. There is a well-articulated implementation, or "knowing-doing" gap, which plagues many fields, including conservation (Knight et al., 2008; Cook et al., 2013; Rose et al., 2019). Conservation interventions regularly fail (Catalano et al., 2019) despite huge commitments of resources, especially when alternative scientific knowledge is not considered within a landscape of traditional management (Pullin et al., 2004; Sutherland et al., 2004). A lack of effective communication between knowledge producers and managers can mean that highly relevant information is overlooked. For instance, restoration efforts can accidentally create ecological traps that damage populations (Hale and Swearer, 2017), and species translocations commonly fail because they lack integration of parallel fields of knowledge, such as animal behavior (Berger-Tal et al., 2020). Conversely, there is wasted scientific and data collection effort which could be more usefully directed toward specific conservation problems (Brodie, 2009; Cook et al., 2013). The issue stems from mutual lack of understanding, common discourse, and organization of evidence; all of which require more relationship-building to increase trust between the communities of conservation practitioners (those who are directly involved in designing and implementing conservation actions) and conservation scientists (those who generate and publish fundamental knowledge that could inform conservation actions). These disconnects are particularly apparent in universities, where scientists are often not in the same organizational units as practitioners or the practitioners are entirely external to the institution.

Scientists studying conservation behavior acutely face the larger conservation implementation gap. Conservation behavior is a sub-field of animal behavior that focuses on understanding species decline, and developing tools for monitoring wildlife and solving conservation problems (Berger-Tal et al., 2011), but is often seen as a specialist subfield within either ecology or evolution, and is sometimes entirely classified outside of biology into areas of psychology. Despite decades-long discussion and research demonstrating the conservation applications of animal behavior research (Caro, 1998; Blumstein and FernándezJuricic, 2010; Berger-Tal et al., 2011; Wong and Candolin, 2015), conservation behavior still fails to have widespread impacts (Caro and Sherman, 2013; Berger-Tal et al., 2015, 2020). Yet, there has never been a better time to generate and use behavioral evidence, given that recent technological innovations in behavioral data collection (animal-borne and environmental remote sensors (Ropert-Coudert and Wilson, 2005), data transmission (communications infrastructure, such as GSM and LoRA), and pattern recognition ( $\mathrm{AI} / \mathrm{machine}$ learning; Valletta et al., 2017) have transformed the pace and scope of behavioral research.

Recent initiatives have identified specific gaps that could improve the application of conservation behavior, such as effective curation and dissemination of scientific evidence (Berger-Tal et al., 2019), prioritizing research areas with known conservation potential (Greggor et al., 2016), and increasing trust between practitioners and scientists (Merkle et al., 2019). Moreover, there has been increasing documentation of the general types of obstacles separating scientists, practitioners and effective conservation action (Sanders et al., 2019; Walsh et al., 2019). Although such endeavors are crucial to improve conservation behavior, in isolation they cannot make effective changes to research application and subsequent conservation outcomes. For instance, simply making behavioral evidence available does not guarantee any change in practice unless the surrounding working norms that guide decision-making actively encourage the use of evidence (Sutherland and Wordley, 2017). Thus, there is a compelling need for wider change within the conservation and behavior communities to tackle the varied disconnects among the fields. We argue that a formalized vision for change is necessary to overcome the complexity and scope of disconnects between fundamental animal behavior research and its application, and can help shape roles for people from varying fields and backgrounds and expand the relevance of behavioral research to real-world problems (Blackwell et al., 2016). We 
propose that a concrete theory of change will serve as a useful tool to achieve this timely, formalized vision.

Theory of change describes a conceptual model for achieving a collective vision, often involving systems-level changes that facilitate modifications to social, working, or environmental conditions (Hayes, 2018). Typically expressed as a visual diagram, theory of change is a tool used by groups of stakeholders interested in depicting their strategies, and the related near-, mid-, and long-term outcomes necessary to realize a collective mission. Change models clarify the linkages between actions and resulting outcomes that support the collective vision, constructing implicit hypotheses about how change is expected to occur; i.e., "if we implement certain actions, then certain changes will occur." Formal change models also reveal underlying assumptions that may be important when trying to influence social change, and simultaneously recognize facilitators and barriers to change. Change models do not provide specific implementation plans; instead, they articulate how change is expected to take place and what evidence of change to look for along the way, to help develop subsequent implementation plans (ORS Impact, 2004). Although a theory of change results in a concrete product, i.e., a visual diagram, the collaborative process developing it is as valuable as its physical documentation because it can catalyze the beginning of the change process (Reisman et al., 2007; Stachowiak, 2013).

The strength of a theory of change can be gauged by the extent to which outcomes are credible and measurable (Weiss, 1995). Once a high-level theory of change is articulated, it can be applied and refined on smaller scales to achieve more specific goals (e.g., integrating a specific sub-field of science into conservation, or applying a broad model within a particular geopolitical system). As an approach, theory of change has been pivotal in catalyzing large-scale change in contexts such as achieving voluntary, high-quality preschool in California (Parker, 2011) and improving the health, educational success, and developmental stability of children and families in Georgia (Georgia Family Connections Partnership, 2016). Additionally, the process of constructing a change model has been used as an adaptive management tool in conservation (e.g., the Conservation Measures Partnership's Open Standards; https:// cmp-openstandards.org/) to structure strategies that address specific conservation challenges (e.g., combatting the illegal wildlife trade (Biggs et al., 2017) and evaluate the effectiveness of multilateral actions (e.g., assessing a social marketing campaign, Salazar et al., 2019). However, theory-based change models are rarely used in the field of animal behavior, despite the complex issues we tackle in applying animal behavior across disciplines or envisioning changes within our field, which often span conceptual, institutional, and geographic boundaries. For instance, questions stemming from structural issues (e.g., how do we create greater diversity in the field of animal behavior?) to disciplinary overlap (e.g., how do we integrate emerging technologies with animal behavior theory?) that the field regularly faces could be addressed with a change model. As building change models is fairly commonplace in conservation planning, there are further process-oriented reasons why developing a change model related to conservation behavior could help bridge some of the aforementioned disconnects between animal behavior and conservation practice.

Here, we develop a change model designed to better link conservation behavior research with application, to ultimately improve conservation and management solutions. To do this, we target conservation behavior scientists and their operating space (e.g., institutions, funders, etc.) to rally and engage practitioners, develop new communication mechanisms, and cultivate relationships built on mutual trust and respect. By doing so, conservation behavior scientists will more purposefully design research addressing the most pressing environmental problems and will improve communication to ensure that generated knowledge is known by and incorporated into the activities of practitioners. Although practitioners are critical to this shift (Merkle et al., 2019; Dubois et al., 2020) (Table 1), we focus on actions for people on the scientist side of the implementation gap, since the institutional drivers of change operate differently in management settings. We emphasize scientists' role in catalyzing the outcome pathways proposed by this change model because we feel this will have the greatest immediate positive impact in addressing the disconnects we have illustrated. In focusing on optimally integrating behavior and conservation, we do not aim to thoroughly review the successes and failures of past conservation behavior interventions since these have been addressed in detail elsewhere (e.g., Berger-Tal et al., 2011; Caro and Sherman, 2013; Greggor et al., 2020). However, we highlight relevant case studies and examples where appropriate.

\section{METHODOLOGY: HOW WE CREATED A CHANGE MODEL}

We convened a group of 12 professionally diverse conservation behavior researchers, managers, policy advocates, and social scientists over 3 days to articulate a change model that would address perceived gaps in animal behavior and conservation practice. Included were professional facilitators who guided participants to create, clarify, and build consensus about a change model.

First, we identified our main target audience to be conservation behavior scientists and their institutions. We elected this focus because the collective experience of the group allowed us to most clearly articulate the challenges and outcome pathways on the research side of the implementation gap. However, the work of many in the group on the management side allowed us to realistically connect these pathways to management processes that could be later fleshed out in a separate, management-focused change model. Then, we reviewed related theory of change models from other fields to critique their inherent logic and structure, and inform the processes we would apply in generating our own model. Using the revised logic and structure, we: (1) articulated a shared vision that defined the highest-level goals for our change model; (2) identified the broad strategies (i.e., sets of related actions) necessary to achieve these goals; and (3) identified the pathways of associated outcomes, or "results chains" (i.e., changes that result from implementation of the strategies) that would indicate 
TABLE 1 | Case studies of current and desired state of applied conservation behavior research.

Current state: Traditional academic model

Research envisioned with greatest academic impact

in mind. Implications for conservation a secondary

concern. Collaborations between academic

partners encouraged

Funding

Emphasis on novelty. Little support for replication research or management-focused interventions

Research design and data collection

Outcomes
Scientific rigor is the driving consideration within the constraints of funding

New knowledge is created and disseminated in academic journals and academic press-releases
Desired state: Integrated conservation

behavior science

Research envisioned with most effective conservation outcome in mind. Collaborations between academic institutions, and management and land-use stakeholders encouraged

Emphasis on potential management impact. Value placed on cost effectiveness, and potential for collaboration between agencies and stakeholders

Scientific rigor balanced with controls designed with greatest power to test existing tools and interventions or develop new ones that are as useful to the end-user as possible

Research findings are published in open-access journals, incorporated into management guidance documents and successes/failures communicated to the public progress toward our goals (Margoluis et al., 2013; Qiu et al., 2018). We achieved this last step by continually applying a "so that" logical statement, forcing us to be clear about how X (a strategy) achieves Y (an outcome). Overall we aimed to determine the logical steps necessary to move from the current state of conservation behavior research to the desired future state of the field (Table 1).

After articulating the shared vision, we randomly assigned participants to smaller groups and each group independently developed and mapped strategies and pathways of associated outcomes. We then compared the different maps that emerged from each group and collectively questioned the logic and connections between strategies and outcomes. This cross-group assessment refined the outcome pathways until we reached a consensus.

The facilitators documented insights that emerged from the cross-group discussion and identified assumptions; this helped clarify the rationale for the theory of change and articulate how change would be expected to occur. These key assumptions included: (1) that conservation professionals (both scientists and practitioners) and the institutions within which they work have the capacity and willingness to change; (2) change can be accomplished from both the top, by influencing regulations and funding priorities, and from the bottom, from conservation professionals, by considering alternative approaches to conservation challenges; (3) it will be necessary to engage and influence multiple stakeholders, thereby changing the context in which conservation professionals do their work; and (4) that models for change must be flexible/workable for all fields within behavioral or conservation science, and ideally applicable to any locality and ecosystem.

We illustrate and document this process as we feel it is broadly applicable in developing new understanding of how animal behavior research can be applied to other societal priorities. By following similar steps, another group of scientists and stakeholders could develop a change model for applying animal behavior to other fields of practice, such as animal welfare or implementation of One Health strategies (https://www.cdc.gov/ onehealth/index.html).

\section{CHANGE MODEL FOR CONSERVATION BEHAVIOR AND PRACTICE}

We present a framework for change in conservation behavior science and practice (Figure 1). Although this model focuses on the sub-field of conservation behavior, similar principles may be applicable to many of the sub-disciplines of animal behavior (or indeed other scientific disciplines) that aim to apply scientific insights. Although actions in the model are outlined for multiple stakeholders (Table 2), the review focuses on what scientists and scientific institutions can do to shift practices within the conservation behavior field to support evidence uptake and effective partnerships.

Our framework consists of four interdependent strategies that are nested on three levels (Figure 1). We present each strategy, outlining the likely chain of outcomes each would contribute toward the larger goal of integrating animal behavior research into applied conservation strategies. Actions and outcomes at one level likely influence the probability of actions and magnitude of outcomes at other levels. For example, increased awareness of successful conservation applications from the field of behavioral ecology will motivate conservation practitioners to develop meaningful relationships with animal behavior scientists, and vice versa. Concomitantly, increased awareness and relationships will enable further transfer of scientific knowledge to conservation applications where behavior could be useful, while contributing positively to capacity building of effective conservation science.

\section{Training and Capacity Building}

Education and professional training must teach conservation behavior as part of integrated conservation science curricula. These translational curricula expose students and career conservationists to a discipline that has potential uses 


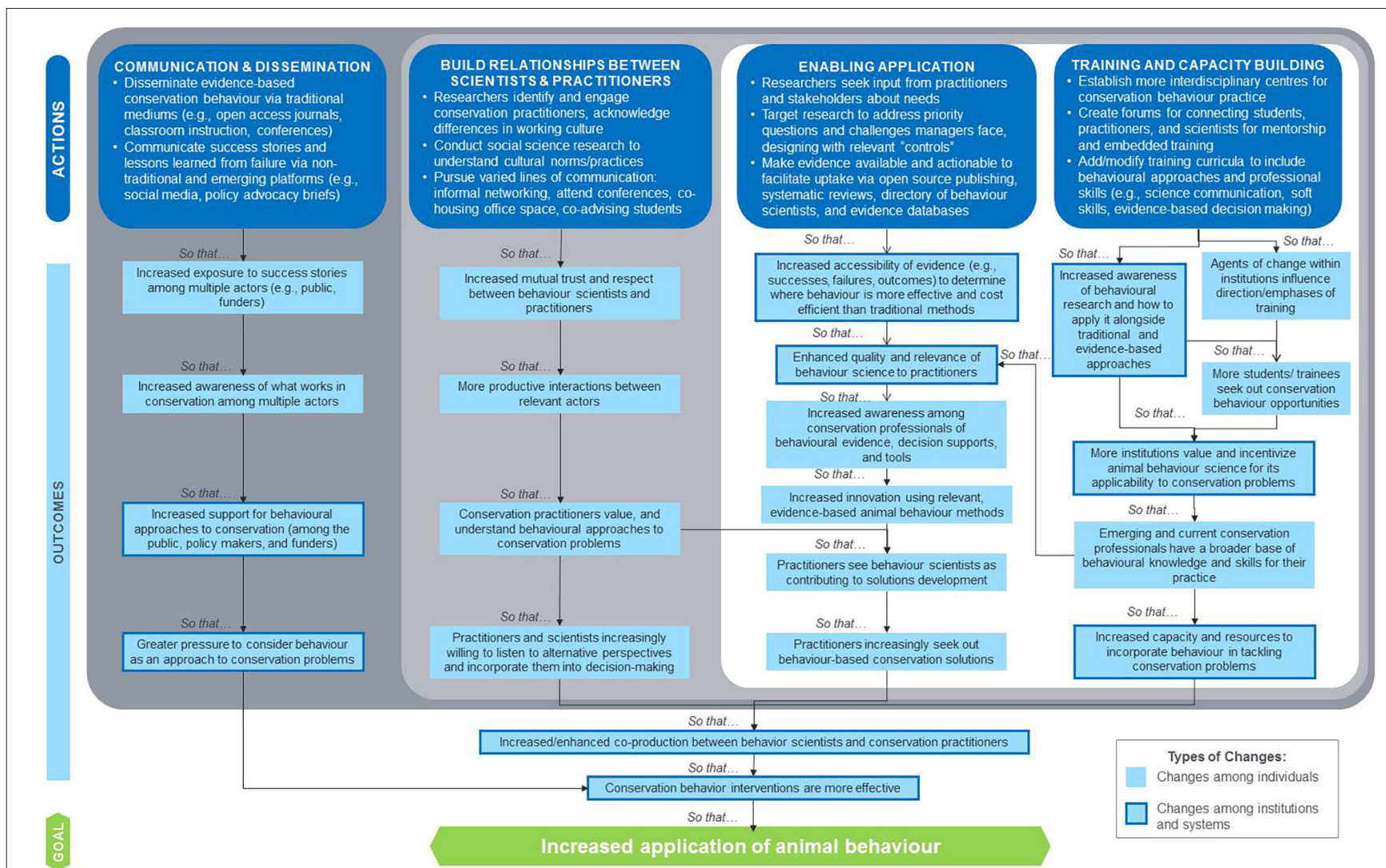

FIGURE 1 | Change model diagram. The model contains four interdependent strategies, nested on three levels. The outermost level (dark gray) sets the landscape for the other strategies, by depicting activities that promote effective communication and dissemination of success, thereby creating a supportive environment for other strategies. The intermediate level (light gray) targets a strengthening of relationships between conservation behavior scientists and practitioners. The innermost level (white) captures the interplay between institutions that enhance training and capacity building, and the infrastructure for making science available. Each strategy outlines a series of actions (dark blue boxes) whose pursuit leads to a logical series of outcomes.

for conservation practice, and normalize evidence-based, solution-oriented decision making. Moreover, an integrated science/application approach to teaching animal behavior or behavioral ecology can also address the major shortcomings that are evident in how traditional science teaches communication, real-world decision-making, conflict resolution, policy, regulatory constraints and implications (Muir and Schwartz, 2009). This action in itself could help promote animal behavior within educational institutions, by connecting the science to the development of skills relevant to the practical application of scientific findings. In addition, the infrastructure (e.g., materials, programs, and "places") to support relationships between animal behavior science and practice must be established. Such learning environments will foster the development of conservation professionals with an interdisciplinary approach to problem solving, along with networking, and other fundamental skills needed to support knowledge integration across disciplinary boundaries (Jacobson and McDuff, 1998; Heckman and Kautz, 2012; Cheruvelil et al., 2014; Toomey et al., 2017). As two emerging examples, ConservationXLabs coordinates a consortium of universities and conservation organizations to develop modules and curricula elements that integrate such fundamental skills into conservation capacity development (https://conservationxlabs.com/transforming-education) and WildHub is offers an online platform with capacity building and professional development video channels for conservation professionals (https://wildhub.community/).

Individual agents of change, such as professors or institutional leaders, can influence the direction of training to emphasize the need for integrating conservation behavior with practice, thereby normalizing this approach as a standard for effective conservation (Pietri et al., 2011; Kelly et al., 2019). When more institutions value applied curricular content that addresses direct conservation challenges, or more generally, teaching the application of knowledge alongside teaching the creation of knowledge, standards for training and inter-institutional relationships will reflect this priority. For instance, learning how conservation funding works and how to write clearly articulated funding proposals that tackle conservation behavior problems would increase the likelihood that students can apply their knowledge later on. Additionally, undergraduate and graduate curriculum and learning materials are also needed 
TABLE 2 | Actors and actions relevant to each strategy.

\begin{tabular}{|c|c|c|c|c|}
\hline Strategy & Student/trainee & Researcher/faculty & Practitioner & Institutional leader \\
\hline $\begin{array}{l}\text { Training and capacity } \\
\text { building }\end{array}$ & $\begin{array}{l}\text { Improve communication } \\
\text { skills and seek experiences } \\
\text { (e.g., internships, select } \\
\text { courses) to learn the } \\
\text { complex factors that affect } \\
\text { conservation decisions (e.g., } \\
\text { regulatory/legal framework, } \\
\text { conservation partnerships, } \\
\text { political constraints, public } \\
\text { perception) }\end{array}$ & $\begin{array}{l}\text { Build and deliver } \\
\text { curricula/training } \\
\text { opportunities that integrate } \\
\text { the expanded fundamental } \\
\text { skills, including } \\
\text { evidence-based decision } \\
\text { making. Produce } \\
\text { open-source materials in } \\
\text { conservation behavior }\end{array}$ & $\begin{array}{l}\text { Engage in professional } \\
\text { development to expand } \\
\text { scientific skills (e.g., attend } \\
\text { workshops at conferences, } \\
\text { learn about new methods) }\end{array}$ & $\begin{array}{l}\text { Structure professional } \\
\text { development, } \\
\text { curricula-change, } \\
\text { recruitment, and retention } \\
\text { practices to value applied, } \\
\text { multidisciplinary } \\
\text { conservation. Provide } \\
\text { co-working spaces for } \\
\text { practitioners and } \\
\text { researchers. Value and } \\
\text { incentivize applied outputs }\end{array}$ \\
\hline Enable application & $\begin{array}{l}\text { Find mentors who represent } \\
\text { various aspects of } \\
\text { conservation behavior, from } \\
\text { basic research to applied } \\
\text { problem solving (e.g., work } \\
\text { with a behavioral ecologist } \\
\text { on explicit conservation } \\
\text { management problems) }\end{array}$ & $\begin{array}{l}\text { Design projects for } \\
\text { addressing specific } \\
\text { conservation problems. } \\
\text { Publish in Open Access } \\
\text { journals and } \\
\text { practitioner-focused outlets, } \\
\text { write systematic reviews, } \\
\text { and understand how } \\
\text { science translates into } \\
\text { decision support tools. Seek } \\
\text { stakeholder engagement. } \\
\text { Attend practitioner }\end{array}$ & $\begin{array}{l}\text { Consult and request } \\
\text { systematic evidence } \\
\text { databases. Embrace } \\
\text { conservation science as a } \\
\text { problem-solving discipline. } \\
\text { Share needs to researchers. } \\
\text { Identify management } \\
\text { actions that could benefit } \\
\text { from research. Encourage } \\
\text { funding directed toward } \\
\text { research used to inform } \\
\text { management }\end{array}$ & $\begin{array}{l}\text { Fund and incentivize open } \\
\text { access science, } \\
\text { translational and } \\
\text { interdisciplinary research. } \\
\text { Support attendance at } \\
\text { management oriented } \\
\text { meetings (e.g., conferences, } \\
\text { species recovery plan } \\
\text { workshops). Hire knowledge } \\
\text { mobilization experts (e.g., } \\
\text { knowledge brokers) }\end{array}$ \\
\hline
\end{tabular}

Build relationships between scientists and practitioners
Communication and dissemination
Gain work experience with on-the-ground conservation professionals (e.g., internships, research experiences, short-term employment, job shadowing). Discuss ideas with practitioners before starting research. Seek applied partners for graduate committees. Get involved in conservation behavior at relevant academic societies (e.g., Animal Behavior Society, Society for Conservation Biology)

Promote your work through social and traditional media channels, seek communication training
Attend practitioner

meetings. Share data and

code. Invite practitioners to co-advise students

Increase co-working

opportunities with

practitioners. Learn about practitioners' experiences and invest in relationships. Invite practitioners to visit research sites, discuss and plan conservation activities (e.g., Open Standards planning), and share their ideas and perspectives. Invest in "icebreakers" and other social activities. Offer cross training opportunities to practitioners

Take responsibility for training students (e.g., social media, website building). Develop and model communication strategy (focus on language and outlet). Establish dialogue and have meaningful conversations with practitioners and other relevant parties.

Communicate with businesses and public members opposed to conservation actions (e.g., public hearings)
Share stories illustrating successful research applications with colleagues. Attend scientific meetings (in person or virtually). Include research needs/knowledge gaps in conservation planning documents
Share and promote collaborative research. Communicate success of institutional strategy. Incorporate success into the identity of the institution. Celebrate cross-institution partnerships. Provide facilities for virtual meetings and archiving meeting content. Enable staff to express scientific opinion in political lobbying contexts to support practitioner efforts 
to articulate successful and unsuccessful conservation cases where less traditional areas of science and practice have been applied cooperatively to solve conservation problems. For example, incorporating the science of animal behavior into management practice has been crucial for improving the success of conservation breeding programs (Martin-Wintle et al., 2015), conservation translocation programs (Bell, 2016; Shier, 2016) and methods to reduce human-animal collisions (Blackwell et al., 2016). Institutions can also lend legitimacy for those who wish to apply behavior by developing online certificate programs, such as a conservation behavior certificate for active or future practitioners, or for those who wish to apply behavior while working in a non-research field.

Institutional structure needs to also support and incentivize integrated behavioral science and conservation practice (e.g., Cvitanovic et al., 2015). Just as academic institutions partner with government and industry to foster technological innovation (e.g., Triple Helix of Innovation, Etzkowitz and Zhou, 2018), models of cross-field conservation partnerships show promise (e.g., Cooperative Research Units with United States Geological Survey, Merkle et al., 2019). Such structural support can take many forms in conservation behavior. These include colocating regulatory, $\mathrm{NGO}$, and policy partners with institutional academic units (e.g., the Cambridge Conservation Initiative), or prioritizing internal-external partnerships in the hiring, merit, and promotion practices and policies of academic units within institutions (as implemented by many land-grant and marine institutions in the US). From an instructional point of view, building curricula that support co-working and colearning between conservation practitioners and students in academic institutions will help those institutions increase the probability of successful career steps immediately following graduation, which will strengthen the impact of the institutions on society and attract more students into animal behavior and conservation courses.

However, to be successful, such efforts need to include professionally and racially diverse teams (an element that is sorely lacking in many conservation and animal behavior programs currently), clearly articulated goals, effective leaders, and funding incentives (Cvitanovic et al., 2018). Additionally, targeted outreach from conservation professionals in forums where emerging or early career scientists and practitioners exchange ideas may help guide students to being effective conservation professionals and acquire key skills. These actions will drive a feedback loop from individuals to institutions, normalizing integrated conservation education and professional development, and producing graduates and career professionals armed with a wide knowledge of appropriate scientific tools for effectively addressing conservation challenges where behavior can be applied.

\section{Enabling Application}

To increase the quality of conservation behavior evidence available to practitioners, two changes in research and science are required. First, conservation behaviorists must ensure that their research is highly relevant to practitioners (Laurance et al., 2012; Greggor et al., 2016), which involves a process of forming research questions that is less focused on prestige and impact factors than the current norm in academic institutions. We contend that scientists often come to the conservation table with preconceived research ideas generated without an understanding of practitioners' needs. Meanwhile, practitioners must prioritize systematic implementation of outcomes rather than evaluating a range of possible approaches that could inform practices. These are major causes of translational failures. To increase applicability, scientists should start with the conservation problem first (constraints, opportunities, threats), then design behavioral research tailored to address the problem. Recommended actions include identifying relevant stakeholders, including the people and communities who are culturally and/or economically linked to the site of conservation action, and increasing dialogue with practitioners and other decision makers during the planning stages of a research program (Lundquist and Granek, 2005). Identifying where to focus applied behavioral research may take the form of strategic conservation planning (Schwartz et al., 2012), horizon scanning (Greggor et al., 2016), or other efforts to convene stakeholders to ensure their priorities are understood and incorporated, when suitable, into research programs (Land et al., 2017). Stakeholder engagement at various stages of the research process, including at early stages when acquiring funding or planning student theses, ensures that research targets practitioners' highest priorities and encourages later co-production of research (e.g., Meadow et al., 2015). For instance, funding at government agencies and NGOs is most often tagged to specific conservation actioni.e., the intervention type is already predetermined. Therefore, government agencies and NGOs rarely have the liberty to "experiment" and set up studies where they evaluate the relative effectiveness of different interventions. If behaviorists design studies that test the effectiveness of ongoing and implemented solutions, using relevant "controls" and counterfactuals, and find the funding separately to the agencies and NGOs, they increase likelihood that their research outcomes would be applied (Beier et al., 2017).

Early stakeholder engagement can also help identify areas where behavioral research may not be the best tool for a given intervention. For example, a manager may deal with a habitat restoration project that failed to attract target species to settle. A researcher specializing in sensory or movement ecology may offer an explanation involving how animals perceive their environment and make habitat settlement decisions, and suggest a behaviorally-based research project to inform management action (Hale et al., 2018; Greggor et al., 2020). However, if the habitat restoration failed because it did not align with the beliefs and priorities of local people, then insight from a conservation social scientist may be more effective, by examining communities' motivations and needs, leading to public engagement strategies for project support (e.g., Kittinger et al., 2016; Amel et al., 2017). It is essential that conservation behaviorists acknowledge the limitations of behavioral work in being suited to solve a subset of wider conservation problems (Caro, 2016), so recommendations can be implementable, focused, and effective.

Second, conservation behaviorists must make evidence accessible to ensure uptake by practitioners, who may intend 
to incorporate the latest scientific findings, but have difficulty identifying appropriate scientific contacts or finding relevant research (Walsh et al., 2014). More generally, scientists must develop new mechanisms to make scientific information and expertise available, including evidence of null results, to help justify when and where behavior is more cost-effective or efficient than traditional management methods. Recommended actions tackle various levels of the evidence hierarchy (sensu Dicks et al., 2014), including conducting systematic reviews to synthesize research about specific conservation problems (Collaboration for Environmental Evidence, 2018; Berger-Tal et al., 2019); publishing in open access journals (Cvitanovic et al., 2015); placing research data and code in data repositories so that they can be reproduced or built upon; creating a directory of willing and vetted scientists to assist with conservation problem-solving; and facilitating the development of online searchable databases for conservation solutions. The latter has gained traction in the form of Conservation Evidence (www.conservationevidence.com), which allows practitioners to search for outcomes of specific conservation interventions in particular taxonomic groups. The need for open evidence goes both ways; by finding ways to make conservation agency reports available for easy access, practitioners can also contribute toward the evidence base (e.g., Applied Ecology Resources by the British Ecological Society). Institutions and funding bodies can encourage open science practices (https://www.cos.io/) by setting publishing standards, providing support for open access fees and data/gray literature repositories. Some agencies, such as the US Forest Service, already do this by encouraging their Research Scientists to create General Technical Reports, written and publicized for ground management staff.

If these activities are successful, practitioners will become increasingly able to find relevant behavioral evidence and actively engage with conservation behaviorists. The availability of readily accessible evidence/data may facilitate decision-making or catalyze new solutions to existing problems (Walsh et al., 2014). With these tools and processes in place, practitioners and scientists can work hand-in-hand to co-produce scientific solutions to conservation problems (e.g., Lemos and Morehouse, 2005; see Beier et al., 2017 for recommendations on effective co-production).

\section{Building Relationships Between Scientists and Practitioners}

Scientists, including behavioral biologists, tend to favor bold intervention and experimentation to maximize information gain, whereas agency staff are typically required to take a more conservative, risk-averse approach. These differences are easily understood when viewed from the perspectives and realities these different actors face (Meek et al., 2015; Merkle et al., 2019). Academics are many times rewarded for taking a "high-risk, high-gain" approach, which when successful, may indeed lead to great scientific advancements (Hyman, 2013). This makes academics far more likely to suggest novel approaches that may seem hazardous to many practitioners. In contrast, when agency staff make decisions, they must consider many stakeholders, including potential criticism from the public, existing laws, political pressure, economic complications and the need to follow established norms. Moreover, the agency funding structure often does not allow for experimentation when enacting conservation interventions. In light of decision uncertainty, practitioners often rely on colleagues and "expert knowledge" to guide their decisions (Pullin et al., 2004) or prefer to focus on "learning while doing" (as opposed to ex ante learning) (Dubois et al., 2020). Moreover, novel information must come from a trusted and respected source (Young et al., 2016) and align with the mission and goals of the organization.

Conservation outcomes can be improved by developing valued professional relationships between conservation behaviorists and conservation practitioners that appreciate these differences (Hulme, 2014). This requires a foundation of mutual trust and respect that can be earned through a series of actions initiated by scientists or practitioners at an individual or institutional level. For example, increased overlap in professional networking between scientists and practitioners can improve transfer of knowledge for decision making (Young et al., 2016). Having greater overlap in training for students destined for research and for management-focused careers can help build shared comradeship and a foundation for later networking. Additionally, co-housing scientists within agencies can help break down barriers, yet we recognize that issues with working norms and expectations may still arise (Roux et al., 2019). By studying and understanding the working environments and priorities of various conservation professionals, conservation behaviorists can improve the transfer, absorption, and evaluation of scientific knowledge into conservation agencies and decisions (Nguyen et al., 2017).

Both conservation behaviorists and practitioners can improve working relationships through simple actions such as formal or informal opportunities to share knowledge. We recommend inviting external conservation professionals to scientific events; for example, in the United States, the National Oceanic and Atmospheric Association's (NOAA) Southwest Fisheries Science Center invites their regulatory partners to attend periodic events (in person or remotely), where scientists share brief presentations of their work. Such a setup provides an easy access point for improved knowledge transfer, particularly with the ever-growing option for virtual participation (via Zoom, live-streaming, YouTube, etc.). Alternatively, conservation professionals may request presentations on specific behavioral topics or technologies to improve their effectiveness. At an institutional level, incentives and opportunities for co-production can be fostered by holding reciprocal meetings with behavioral biologists and practitioners, where each provides background information on their needs, potential and limitations, and the working environment (e.g., institutional norms). Such a setup can encourage co-advising graduate students, whereby inviting practitioner partners to be on thesis and dissertation committees can help build relationships and foster co-working on research that is of mutual interest. Opportunities for outreach also exist at the individual level; for example, scientists can invite practitioners to participate in fieldwork. To be clear, we are not advocating "dumping" knowledge, but rather establishing 
long-term relationships that involve bi-directional exchange of ideas and knowledge (Cook et al., 2013; Young et al., 2016). Finally, attending conferences (even virtually), that are geared toward wildlife societies or other venues for practitioners can increase overlap and chances for networking. Some conservation societies (e.g., the Society for Conservation Biology) have behavior working groups, which increase the presence and legitimacy of behavioral interventions. Moreover, there are ways to better engage with applied research topics within existing behavioral societies, such as the Animal Behavior Society's Conservation Committee (https://www.animalbehaviorsociety. org/web/conservation.php) and annual symposia.

Combined, these actions will increase trust and respect between conservation behaviorists and practitioners, leading to more productive and mutually beneficial interactions. For instance, such collaborations may help create effective conservation solutions, and also open up new funding opportunities for behaviorists, if partnering with NGO or agency sponsors [e.g., United States Department of Agriculture (USDA), NOAA, etc.]. These collaborations rely on the understanding that behavior will not solve all conservation problems, and that conservation science, policy, and regulation are not static. Acknowledging the legitimate strengths, limitations, and applicability of behavior to conservation management can lead to enhanced trust and appreciation for an integrative approach to conservation science.

\section{Communication and Dissemination of Success}

Disseminating conservation outcomes and celebrating conservation successes that use insights from behavior are critical for supporting continued efforts toward integrating behavior and conservation. In a world full of dismal conservation news, success stories provide hope and fuel determination to persist in conservation efforts (Swaisgood and Sheppard, 2010; Leslie et al., 2013). Although awareness alone may not be enough to catalyze behavioral change (Heberlein, 2012), news of success within a greater backdrop of institutional change offers opportunities to reinforce conservation behavior practices, and may create enthusiasm from outside sources that can apply pressure to encourage change. Animal behavior is a powerful storyteller, which can be used to increase support for creative conservation solutions among external influencers, such as policy makers, funders, and the general public (Martín-López et al., 2007; Marzluff and Swift, 2017). However, the lessons learned from conservation failures involving behavior should also be shared, to cement the idea that evidence is gained from conservation failures which contributes to the building of future conservation successes.

Several strategies can be implemented for disseminating conservation success stories. Publishing behavior-focused case studies in open access journals facilitates knowledge transfer to those without institutional access to journals. Posting on social media (e.g., academic Twitter) can increase both academic and public awareness. Condensing results into a simplified format (e.g., infographics, graphical abstracts, short videos) with accessible language can help reach policymakers, especially if packaged in the context of their decision-making efforts and impacts on their constituents. Presenting at professional conferences and meetings, especially ones where managers may be in attendance, can communicate successful strategies to colleagues. Integrating conservation behavior stories into scientific communication venues and opportunities, including scientific communication conferences and the production of podcasts and short videos, might be fruitful forms of engagement for scientists. Lastly, success stories can be featured in classroom instruction and detailed accounts can be described in funding and grant reports. Such success stories could reach beyond the walls of classes in the biological and environmental sciences, to courses on communication, advocacy, and environmental justice, to name but a few areas in which conservation behaviorists could extend their reach on university campuses.

As success stories spread among non-professionals, several benefits can be realized. First is the recognition among multiple stakeholders that conservation behavior efforts can succeed, even in complex and controversial political environments (McAfee et al., 2019). Policymakers like to be on the winning team; when the public rallies behind well-told success stories they can push policymakers with their collective voice to apply political pressure and loosen purse strings. Among other funding partners, success validates the effort to raise funds for effective conservation efforts. Also, increased awareness of conservation success in the community of funders, NGOs, businesses, and academics allows for unconventional partners to become aware of specific conservation needs, challenges and efforts, thus opening the door to alternative approaches via collaboration and information sharing (e.g., Defenders of Wildlife Innovation Funds). Lastly, as success stories generate enthusiasm among stakeholders, effective methodologies are more likely to be adopted by other agencies, institutions, and practitioners, furthering the changes needed to solidify successful approaches.

Success stories can capture the attention of professionals at multiple levels, thus eventually creating a stabilizing pressure from each end of the professional hierarchy. Better integration of diverse scientific approaches to conservation can stimulate creative thought and discussion among conservation professionals, leading to further transformation from traditional to alternative approaches. This process institutionalizes new norms that reward the capacity and willingness to apply behavioral approaches to conservation efforts. As communication builds stakeholder support for alternative approaches to conservation, this support provides feedback to other parts of the change framework, supporting trust and relationship-building.

\section{DISCUSSION}

Although there is a compelling need to overcome barriers between scientists and practitioners (Rose et al., 2019; Sanders et al., 2019; Walsh et al., 2019), there are some effective examples where integration has worked well in conservation behavior (Table 3). Our framework aims to articulate the landscape where 
TABLE 3 | Examples and elements of successful integration of evidence-based conservation behavior.

\begin{tabular}{|c|c|c|}
\hline & $\begin{array}{l}\text { Proactive long-term institutional approach: San Diego Zoo } \\
\text { Global (SDZG) }\end{array}$ & $\begin{array}{l}\text { Reactive problem-oriented approach: Federal Aviation } \\
\text { Administration (FAA) }\end{array}$ \\
\hline Situation & $\begin{array}{l}\text { Wanted to expand mission beyond conservation breeding to wider } \\
\text { conservation action }\end{array}$ & $\begin{array}{l}\text { Faced a large and complex problem: reducing wildlife collisions } \\
\text { with aircraft to enhance safety at commercial airports }\end{array}$ \\
\hline Issues faced & $\begin{array}{l}\text { Reputation and historical priorities of zoo not initially compatible } \\
\text { with conservation managers and agencies }\end{array}$ & $\begin{array}{l}\text { Changes to land use, high bird densities, and species-specific } \\
\text { behavioral responses to aircraft all led to need for more research }\end{array}$ \\
\hline $\begin{array}{l}\text { Actions taken within the } \\
\text { change model framework } \\
\text { (relevant strategy } \\
\text { referenced) }\end{array}$ & $\begin{array}{l}\text { - Communicated and listened to different perspectives, especially } \\
\text { in early planning (Enable Application) } \\
\text { - Fostered relationships and trust between SDZG scientists and } \\
\text { agency partners, sharing successes together (Built } \\
\text { Relationships) } \\
\text { - Fostered critical engagement with local communities, including } \\
\text { internationally, to garner on-the-ground support (Built } \\
\text { Relationships) } \\
\text { - SDZG underwent pivot to adopt approaches meeting regulatory } \\
\text { needs (Enabling Application) } \\
\text { - Attracted funding beyond government grants (Training and } \\
\text { Capacity Building) } \\
\text { - Communicated success stories internally to board members } \\
\text { and to the public via social media, active PR department } \\
\text { (Communication and dissemination) }\end{array}$ & $\begin{array}{l}\text { - Partnered with U.S. Department of Agriculture's National Wildlife } \\
\text { - Tosearch Center (Build relationships) } \\
\text { development, including integrating animal behavior, sensory } \\
\text { ecology, engineering and population biology (Training and } \\
\text { Capacity Building) } \\
\text { - Multi-day trainings were created (by various groups to meet } \\
\text { FAA certification) for airport biologists that incorporate relevant } \\
\text { research findings (Training and Capacity Building) } \\
\text { - Funded science from a range of fields, including wildlife } \\
\text { management, animal behavior and sensory ecology (Enabling } \\
\text { Application) } \\
\text { - FAA produced tailored Advisory Circulars and CertAlerts } \\
\text { guidance documents (available on FAA web page) based on the } \\
\text { research, for airports, flight planners, and pilots (Communication } \\
\text { and dissemination) }\end{array}$ \\
\hline Outcomes & $\begin{array}{l}\text { - Large increase in SDZG-regulatory agency partnerships } \\
\text { - SDZG gained institutional reputation as conservation } \\
\text { - Improblem-solver } \\
\text { - } \text { outcomes } \\
\text { - Acts as behavioral "knowledge broker" to connect agency } \\
\text { needs to partners with relevant behavioral skills }\end{array}$ & $\begin{array}{l}\text { - Research findings are incorporated into guidance documents to } \\
\text { improve management } \\
\text { - Solutions developed, such as: evaluation of radar technology for } \\
\text { tracking birds Gerringer et al., 2016; assessment of behavioral } \\
\text { rules birds use to avoid aircraft DeVault et al., 2015; and } \\
\text { development of aircraft lighting tuned to the avian eye to deter } \\
\text { birds Goller et al., } 2018 \\
\text { - Rate of damaging collisions at airports has declined over the } \\
\text { past } 20 \text { years Dolbeer et al., } 2019\end{array}$ \\
\hline
\end{tabular}

such examples would be the rule rather than the exception. There are several initiatives underway that seek to achieve a similar goal (e.g., the "bright spots" approach, Bennett et al., 2016) and we see them complementing or being incorporated into the change model presented here. Similar to the struggle of applying other areas of behavior, the complex inter-relationships within the model suggest that almost any progress in taking action and reaching outcomes can contribute toward the common vision and goal. Simultaneously, a limited scale of action under any of the four strategies could impact progress toward the overall goal. Crucially, the validity of this change model will require critical appraisal, specifically from conservation managers and practitioners, as actions take place. Evaluating and monitoring the impact of progress in one strategy on others can help determine whether these suggestions actually lead to greater research application. For instance, the assumption that enhanced co-production will lead to more effective conservation behavior interventions has yet to be formally proven in this field, although examples exist from other areas (Nel et al., 2016). Additionally, the applicability of the model to the implementation gap across varying geographic and political environments also needs to be tested. However, the model itself can still be used to structure fruitful conversations between conservation behaviorists and conservation practitioners. Ideally, such feedback permits ongoing modifications to make this model a living document.
We framed our model to focus on conservation behavior researchers and their institutions, but similar models could be adapted to the conservation practitioner perspective, as well as to policy makers who use data to inform policy. Importantly, change models such as this articulate how to apply knowledge. The application of knowledge is something that the US National Institute of Health promotes in their "Bench to Bedside" philosophy and we believe translational research is a concept that can apply to many fields. This framework can be modified to achieve other translational behavioral goals, such as improving the health and welfare of animals and humans. A team of scientists focused on animal welfare, as one such example, could convene with those who implement and monitor welfare in various industry areas and create their own change model using the approaches we describe here. This would lead to a better understanding of how research in animal welfare can be more directly applied to benefit the outcomes for animals in human care. Importantly, creating consequential research can be as intellectually stimulating as creating fundamental research, with the added benefit of providing direct solutions to realworld problems.

\section{AUTHOR CONTRIBUTIONS}

ALG, OB-T, RS, and DB organized and AG and CH facilitated the change model workshop which served as the foundation for 
the paper. All authors participated in the workshop and writing of the paper.

\section{FUNDING}

The Oak Foundation and the San Diego Zoo Institute for Conservation Research contributed funding for the workshop and publishing fees.

\section{REFERENCES}

Amel, E., Manning, C., Scott, B., and Koger, S. (2017). Beyond the roots of human inaction: fostering collective effort toward ecosystem conservation. Science 356, 275-279. doi: 10.1126/science.aal1931

Beier, P., Hansen, L. J., Helbrecht, L., and Behar, D. (2017). A how-to guide for coproduction of actionable science. Conserv. Lett. 10, 288-296. doi: $10.1111 /$ conl.12300

Bell, B. D. (2016). "Behavior based managment: conservation translocations," in Conservation Behavior, eds O. Berger-Tal and D. Saltz (Cambridge: Cambridge University Press), 212-246.

Bennett, E. M., Solan, M., Biggs, R., McPhearson, T., Norström, A. V., Olsson, P., et al. (2016). Bright spots: seeds of a good Anthropocene. Front. Ecol. Environ. 14, 441-448. doi: 10.1002/fee.1309

Berger-Tal, O., Blumstein, D. T., Carroll, S., Fisher, R. N., Mesnick, S. L., Owen, M. A., et al. (2015). A systematic survey of the integration of behavior into wildlife conservation and management. Conserv. Biol. 30, 744-753. doi: $10.1111 /$ cobi.12654

Berger-Tal, O., Blumstein, D. T., and Swaisgood, R. R. (2020). Conservation translocations: a review of common difficulties and promising directions. Anim. Conserv. 23, 121-131. doi: 10.1111/acv.12534

Berger-Tal, O., Greggor, A. L., Macura, B., Adams, C. A., Blumenthal, A., Bouskila, A., et al. (2019). Systematic reviews and maps as tools for applying behavioral ecology to management and policy. Behav. Ecol. 30, 1-8. doi: 10.1093/beheco/ary130

Berger-Tal, O., Polak, T., Oron, A., Lubin, Y., Kotler, B. P., and Saltz, D. (2011). Integrating animal behavior and conservation biology: a conceptual framework. Behav. Ecol. 22, 236-239. doi: 10.1093/beheco/arq224

Berger-Tal, O., and Saltz, D. (2016). Conservation Behavior, Applying Behavioral Ecology to Wildlife Conservation and Management. Cambridge: Cambridge University Press.

Biggs, D., Cooney, R., Roe, D., Dublin, H. T., Allan, J. R., Challender, D. W. S., et al. (2017). Developing a theory of change for a community-based response to illegal wildlife trade. Conserv. Biol. 31, 5-12. doi: 10.1111/cobi.12796

Blackwell, B. F., DeVault, T. L., Fernández-Juricic, E., Gese, E. M., Gilbert-Norton, L., and Breck, S. W. (2016). No single solution: application of behavioural principles in mitigating human-wildlife conflict. Anim. Behav. 120, 245-254. doi: 10.1016/j.anbehav.2016.07.013

Blumstein, D. T., and Fernández-Juricic, E. (2010). A Primer on Conservation Behaviour. Sunderland, MA: Sinauer.

Brodie, J. F. (2009). Is research effort allocated efficiently for Conservation? Felidae as a global case study. Biodivers. Conserv. 18, 2927-2939. doi: 10.1007/s10531-009-9617-3

Broom, D. M., and Fraser, A. F. (2015). Domestic Animal Behaviour and Welfare. 5th Edn. Tarxien: Gutenberg Press.

Caro, T. (1998). Behavioral Ecology and Conservation Biology. Oxford University Press. Available online at: https://books.google.com/books?id= dNOVSQBtFrMC

Caro, T. (2016). Behavior and conservation, conservation and behavior. Curr. Opin. Behav. Sci. 12, 97-102. doi: 10.1016/j.cobeha.2016.09.008

Caro, T., and Sherman, P. W. (2013). Eighteen reasons animal behaviourists avoid involvement in conservation. Anim. Behav. 85, 305-312. doi: 10.1016/j.anbehav.2012.11.007

\section{ACKNOWLEDGMENTS}

We would like to thank ORS Impact and Maggie Drummond for helping make the workshop that led to this paper possible, and to the Oak Foundation for contributing funding. We would also like to thank Naomi Lewandoski and Michael Asaro for offering comments on a draft of the paper. Contributions of TD were partially supported by the U.S. Department of Energy under award DE-EM0004391 to the University of Georgia Research Foundation.

Catalano, A. S., Lyons-White, J., Mills, M. M., and Knight, A. T. (2019). Learning from published project failures in conservation. Biol. Conserv. 238:108223. doi: 10.1016/j.biocon.2019.108223

Cheruvelil, K. S., Soranno, P. A., Weathers, K. C., Hanson, P. C., Goring, S. J., Filstrup, C. T., et al. (2014). Creating and maintaining high-performing collaborative research teams: the importance of diversity and interpersonal skills. Front. Ecol. Environ. 12, 31-38. doi: 10.1890/130001

Collaboration for Environmental Evidence (2018). About Us. Available online at: http://www.environmentalevidence.org/ (Accessed February 3, 2018).

Cook, C. N., Mascia, M. B., Schwartz, M. W., Possingham, H. P., and Fuller, R. A. (2013). Achieving conservation science that bridges the knowledge-action boundary. Conserv. Biol. 27, 669-678. doi: 10.1111/cobi. 12050

Cvitanovic, C., Hobday, A. J., van Kerkhoff, L., Wilson, S. K., Dobbs, K., and Marshall, N. A. (2015). Improving knowledge exchange among scientists and decision-makers to facilitate the adaptive governance of marine resources: a review of knowledge and research needs. Ocean Coast. Manag. 112, 25-35. doi: 10.1016/j.ocecoaman.2015.05.002

Cvitanovic, C., Löf, M. F., Norström, A. V., and Reed, M. S. (2018). Building university-based boundary organisations that facilitate impacts on environmental policy and practice. PLOS ONE 13:e0203752. doi: 10.1371/journal.pone.0203752

DeVault, T. L., Blackwell, B. F., Seamans, T. W., Lima, S. L., and FernandezJuricic, E. (2015). Speed kills: ineffective avian escape responses to oncoming vehicles. Proc. R. Soc. B 282:20142188. doi: 10.1098/rspb.2014. 2188

Dicks, L. V., Walsh, J. C., and Sutherland, W. J. (2014). Organising evidence for environmental management decisions: a “4S” hierarchy. Trends Ecol. Evol. 29, 607-613. doi: 10.1016/j.tree.2014.09.004

Dolbeer, R. A., Begier, M. J., Miller, P. R., Weller, J. R., and Anderson, A. L. (2019). Wildlife Strikes to Civil Aircraft in the United States 19902018. Washington, DC: United States Department of Transportation Federal Aviation Administration.

Dubois, N. S., Gomez, A., Carlson, S., and Russell, D. (2020). Bridging the researchimplementation gap requires engagement from practitioners. Conserv. Sci. Pract. 2:e134. doi: 10.1111/csp2.134

Etzkowitz, H., and Zhou, C. (2018). The Triple Helix: Univeristy-IndustryGovernment Innovation and Entrepreneurship. 2nd Edn. New York, NY: Routeledge; Taylor and Francis Group.

Georgia Family Connections Partnership (2016). Theory of Change. Available online at: https://gafcp.org/wp-content/uploads/2016/08/GAFCP_Theory_ Map.pdf.

Gerringer, M. B., Lima, S. L., and DeVault, T. L. (2016). Evaluation of an avian radar system in a midwestern landscape. Wildl. Soc. Bull. 40, 150-159. doi: $10.1002 /$ wsb.614

Goller, B., Blackwell, B. F., DeVault, T. L., Baumhardt, P. E., and Fernández-Juricic, E. (2018). Assessing bird avoidance of high-contrast lights using a choice test approach: implications for reducing human-induced avian mortality. PeerJ 6:e5404. doi: 10.7717/peerj.5404

Greggor, A. L., Berger-Tal, O., and Blumstein, D. T. (2020). The rules of attraction: the necessary role of animal cognition in explaining conservation failures and successes. Annu. Rev. Ecol. Evol. Syst. 51, 483-503. doi: 10.1146/annurev-ecolsys-011720-103212 
Greggor, A. L., Berger-Tal, O., Blumstein, D. T., Angeloni, L., Bessa-Gomes, C., Blackwell, B. F., et al. (2016). Research priorities from animal behaviour for maximising conservation progress. Trends Ecol. Evol. 31, 953-964. doi: 10.1016/j.tree.2016.09.001

Hale, R., Coleman, R., Sievers, M., Brown, T. R., and Swearer, S. E. (2018). Using conservation behavior to manage ecological traps for a threatened freshwater fish. Ecosphere 9:e02381. doi: 10.1002/ecs2.2381

Hale, R., and Swearer, S. E. (2017). When good animals love bad restored habitats: how maladaptive habitat selection can constrain habitat restoration. J. Appl. Ecol. 54, 1478-1486. doi: 10.1111/1365-2664.12829

Hayes, J. (2018). The Theory and Practice of Change Management. 5th Edn. London: Palgrave Macmillan.

Heberlein, T. A. (2012). Navigating environmental attitudes. Conserv. Biol. 26, 583-585. doi: 10.1111/j.1523-1739.2012.01892.x

Heckman, J. J., and Kautz, T. D. (2012). Hard evidence on soft skills. Natl. Bur. Econ. Res. 19, 451-464. doi: 10.3386/w18121

Hulme, P. E. (2014). Bridging the knowing-doing gap: know-who, knowwhat, know-why, know-how and know-when. J. Appl. Ecol. 51, 1131-1136. doi: $10.1111 / 1365-2664.12321$

Hyman, A. A. (2013). Funding innovative science. Science 339:119. doi: $10.1126 /$ science. 1234741

Jacobson, S. K., and McDuff, M. D. (1998). Training idiot savants: the lack of human dimensions in conservation biology. Conserv. Biol. 12, 263-267. doi: 10.1046/j.1523-1739.1998.97235.x

Kelly, R., Mackay, M., Nash, K. L., Cvitanovic, C., Allison, E. H., Armitage, D., et al. (2019). Ten tips for developing interdisciplinary socio-ecological researchers. Socio Ecol Pract. Res. 1, 149-161. doi: 10.1007/s42532-019-00018-2

Kittinger, J. N., Bambico, T. M., Minton, D., Miller, A., Mejia, M., Kalei, N., et al. (2016). Restoring ecosystems, restoring community: socioeconomic and cultural dimensions of a community-based coral reef restoration project. Reg. Environ. Chang. 16, 301-313. doi: 10.1007/s10113-013-0572-x

Knight, A. T., Cowling, R. M., Rouget, M., Balmford, A., Lombard, A. T., and Campbell, B. M. (2008). Knowing but not doing: selecting priority conservation areas and the research-implementation gap. Conserv. Biol. 22, 610-617. doi: 10.1111/j.1523-1739.2008.00914.x

Land, M., Macura, B., Bernes, C., and Johansson, S. (2017). A five-step approach for stakeholder engagement in prioritisation and planning of environmental evidence syntheses. Environ. Evid. 6, 1-7. doi: 10.1186/s13750-017-0104-0

Laurance, W. F., Koster, H., Grooten, M., Anderson, A. B., Zuidema, P. A., Zwick, S., et al. (2012). Making conservation research more relevant for conservation practitioners. Biol. Conserv. 153, 164-168. doi: 10.1016/j.biocon.2012.05.012

Lemos, M. C., and Morehouse, B. J. (2005). The co-production of science and policy in integrated climate assessments. Glob. Environ. Chang. 15, 57-68. doi: 10.1016/j.gloenvcha.2004.09.004

Leslie, H. M., Goldman, E., Mcleod, K. L., Sievanen, L., Balasubramanian, H., Cudney-Bueno, R., et al. (2013). How good science and stories can go handin-hand. Conserv. Biol. 27, 1126-1129. doi: 10.1111/cobi.12080

Lundquist, C. J., and Granek, E. F. (2005). Strategies for successful marine conservation: integrating socioeconomic, political, and scientific factors. Conserv. Biol. 19, 1771-1778. doi: 10.1111/j.1523-1739.2005.00279.x

Marchant-Forde, J. N. (2015). The science of animal behavior and welfare: challenges, opportunities, and global perspective. Front. Vet. Sci. 2:16. doi: 10.3389/fvets.2015.00016

Margoluis, R., Stem, C., Swaminathan, V., Brown, M., Johnson, A., Placci, G., et al. (2013). Results chains: a tool for conservation action design, management, and evaluation. Ecol. Soc. 18:22. doi: 10.5751/ES-05610180322

Martín-López, B., Montes, C., and Benayas, J. (2007). The non-economic motives behind the willingness to pay for biodiversity conservation. Biol. Conserv. 139, 67-82. doi: 10.1016/j.biocon.2007.06.005

Martin-Wintle, M. S., Shepherdson, D., Zhang, G., Zhang, H., Li, D., Zhou, X., et al. (2015). Free mate choice enhances conservation breeding in the endangered giant panda. Nat. Commun. 6:10125. doi: 10.1038/ncomms 10125

Marzluff, J. M., and Swift, K. N. (2017). Connecting animal and human cognition to conservation. Curr. Opin. Behav. Sci. 16, 87-92. doi: 10.1016/j.cobeha.2017.04.005
McAfee, D., Doubleday, Z. A., Geiger, N., and Connell, S. D. (2019). Everyone loves a success story: optimism inspires conservation engagement. Bioscience 69, 274-281. doi: 10.1093/biosci/biz019

Meadow, A. M., Ferguson, D. B., Guido, Z., Horangic, A., Owen, G., and Wall, T. (2015). Moving toward the deliberate coproduction of climate science knowledge. Weather. Clim. Soc. 7, 179-191. doi: 10.1175/WCAS-D-14-00050.1

Meek, M. H., Wells, C., Tomalty, K. M., Ashander, J., Cole, E. M., Gille, D. A., et al. (2015). Fear of failure in conservation: the problem and potential solutions to aid conservation of extremely small populations. Biol. Conserv. 184, 209-217. doi: 10.1016/j.biocon.2015.01.025

Merkle, J. A., Anderson, N. J., Baxley, D. L., Chopp, M., Gigliotti, L. C., Gude, J. A., et al. (2019). A collaborative approach to bridging the gap between wildlife managers and researchers. J. Wildl. Manage. 83, 1644-1651. doi: $10.1002 /$ jwmg.21759

Muir, M. J., and Schwartz, M. W. (2009). Academic research training for a nonacademic workplace: a case study of graduate student alumni who work in conservation. Conserv. Biol. 23, 1357-1368. doi: 10.1111/j.1523-1739.2009.01325.x

Nel, J. L., Roux, D. J., Driver, A., Hill, L., Maherry, A. C., Snaddon, K., et al. (2016). Knowledge co-production and boundary work to promote implementation of conservation plans. Conserv. Biol. 30, 176-188. doi: 10.1111/cobi.12560

Nguyen, V. M., Young, N., and Cooke, S. J. (2017). A roadmap for knowledge exchange and mobilization research in conservation and natural resource management. Conserv. Biol. 31, 789-798. doi: 10.1111/cobi,.12857

ORS Impact (2004). Theory of Change: A Practical Tool for Action, Results and Learning. Available online at: https://www.orsimpact.com/directory/Pathwaysfor - Change- 10. htm? categories $=47264$ andkeywords $=$ andpg $=3 \_4$

Parker, W. C. (2011). Constructing public schooling today: derision, multiculturalism, nationalism. Educ. Theory 61, 413-432. doi: 10.1111/j.1741-5446.2011.00412.x

Pietri, D., McAfee, S., Mace, A., Knight, E., Rogers, L., and Chornesky, E. (2011). Using science to inform controversial issues: a case study from the California ocean science trust. Coast. Manag. 39, 296-316. doi: 10.1080/08920753.2011.566118

Pullin, A. S., Knight, T. M., Stone, D. A., and Charman, K. (2004). Do conservation managers use scientific evidence to support their decision-making? Biol. Conserv. 119, 245-252. doi: 10.1016/j.biocon.2003.11.007

Qiu, J., Game, E. T., Tallis, H., Olander, L. P., Glew, L., Kagan, J. S., et al. (2018). Evidence-based causal chains for linking health, development, and conservation actions. Bioscience 68, 182-193. doi: 10.1093/biosci/bix167

Reisman, J., Gienapp, A., and Stachowiak, S. (2007). A Guide to Measuring Advocacy and Policy. Available online at: https://www.orsimpact.com/ DirectoryAttachments/132018_15221_867_a_guide_to_measuring_advocacy_ and_policy.pdf

Ropert-Coudert, Y., and Wilson, R. P. (2005). Trends and perspectives in animalattached remote sensing. Front. Ecol. Environ. 3, 437-444. doi: 10.1890/15409295(2005)003[0437:TAPIAR]2.0.CO;2

Rose, D. C., Amano, T., González-Varo, J. P., Mukherjee, N., Robertson, R. J., Simmons, B. I., et al. (2019). Calling for a new agenda for conservation science to create evidence-informed policy. Biol. Conserv. 238:108222. doi: 10.1016/j.biocon.2019.108222

Roux, D. J., Kingsford, R. T., Cook, C. N., Carruthers, J., Dickson, K., and Hockings, M. (2019). The case for embedding researchers in conservation agencies. Conserv. Biol. 33, 1266-1274. doi: 10.1111/cobi.13324

Salazar, G., Mills, M., and Veríssimo, D. (2019). Qualitative impact evaluation of a social marketing campaign for conservation. Conserv. Biol. 33, 634-644. doi: $10.1111 /$ cobi.13218

Sanders, M. J., Miller, L., Bhagwat, S. A., van der Grient, J. M. A., and Rogers, A. D. (2019). Practitioner insights as a means of setting a context for conservation. Conserv. Biol. 34, 113-124. doi: 10.1111/cobi.13394

Schwartz, M. W., Deiner, K., Forrester, T., Grof-Tisza, P., Muir, M. J., Santos, M. J., et al. (2012). Perspectives on the open standards for the practice of conservation. Biol. Conserv. 155, 169-177. doi: 10.1016/j.biocon.2012.06.014

Shier, D. M. (2016). "Manipulating animal behavior to ensure reintroduction success," in Conservation Behavior: Applying Behavioral Ecology to Wildlife Conservation and Management, eds O. Berger-Tal and D. Saltz (Cambridge: Cambridge University Press), 275-304. 
Stachowiak, S. (2013). Pathways for Change: 10 Theories to Inform Advocacy and Policy Change Efforts. Available online at: https://www.orsimpact.com/ directory $/$ Pathways-for- Change- $10 . \mathrm{htm}$ ? categories $=47264$ andkeywords $=$ andpg $=3 \_4$

Sutherland, W. J., Pullin, A. S., Dolman, P. M., and Knight, T. M. (2004), The need for evidence-based conservation. Trends Ecol. Evol. 19, 305-308. doi: $10.1016 /$ j.tree.2004.03.018

Sutherland, W. J., and Wordley, C. (2017). Evidence complacency hampers conservation. Nat. Ecol. Evol. 1, 1215-1216. doi: 10.1038/s41559-017-0244-1

Swaisgood, R. R., and Sheppard, J. K. (2010). The culture of conservation biologists: show me the hope! Bioscience 60, 626-630. doi: 10.1525/bio.2010.60.8.8

Toomey, A. H., Knight, A. T., and Barlow, J. (2017). Navigating the space between research and implementation in conservation. Conserv. Lett. 10, 619-625. doi: $10.1111 /$ conl.12315

Valletta, J. J., Torney, C., Kings, M., Thornton, A., and Madden, J. (2017). Applications of machine learning in animal behaviour studies. Anim. Behav. 124, 203-220. doi: 10.1016/j.anbehav.2016.12.005

Walsh, J. C., Dicks, L. V., Raymond, C. M., and Sutherland, W. J. (2019). A typology of barriers and enablers of scientific evidence use in conservation practice. J. Environ. Manage. 250:109481. doi: 10.1016/j.jenvman.2019. 109481

Walsh, J. C., Dicks, L. V., and Sutherland, W. J. (2014). The effect of scientific evidence on conservation practitioners' management decisions. Conserv. Biol. 29, 88-98. doi: 10.1111/cobi.12370
Weiss, C. H. (1995). "Nothing as practical as good theory: explaining theory-based evaluation for comprehensive community initiatives for children and families," in New Approaches to Evaluating Community Initiatives: Concepts, Methods and Concepts, eds J. B. Connell, A. C. Kubsich, L. B. Schorr, and C. H. Weiss (Washington, DC: Aspen Institute). p. 62-95.

Wong, B. B. M., and Candolin, U. (2015). Behavioral responses to changing environments. Behav. Ecol. 26, 665-673. doi: 10.1093/beheco/aru183

Young, N., Nguyen, V. M., Corriveau, M., Cooke, S. J., and Hinch, S. G. (2016). Knowledge users' perspectives and advice on how to improve knowledge exchange and mobilization in the case of a co-managed fishery. Environ. Sci. Policy 66, 170-178. doi: 10.1016/j.envsci.2016.09.002

Conflict of Interest: The authors declare that the research was conducted in the absence of any commercial or financial relationships that could be construed as a potential conflict of interest.

Copyright (C) 2021 Greggor, Berger-Tal, Swaisgood, Cooke, DeVault, FernándezJuricic, Gienapp, Hall, Hostetter, Owen, Rankin, Ruppert, Swaddle and Blumstein. This is an open-access article distributed under the terms of the Creative Commons Attribution License (CC BY). The use, distribution or reproduction in other forums is permitted, provided the original author(s) and the copyright owner(s) are credited and that the original publication in this journal is cited, in accordance with accepted academic practice. No use, distribution or reproduction is permitted which does not comply with these terms. 